\title{
Influence of rainfall space-time variability over the Ouémé basin in Benin
}

\author{
T. GASCON, T. VISCHEL, T. LEBEL, G. QUANTIN, T. PELLARIN, \\ V. QUATELA, D. LEROUX \& S. GALLE \\ LTHE (UMR 5564), Univ. Grenoble, IRD, CNRS, Grenoble, France \\ tania.gascon@ujf-grenoble.fr
}

\begin{abstract}
In West Africa, the concomitant occurrence of extreme droughts and damaging floods points to the urgent need for linking the climate variability at various time scales (daily to decadal) to its impact in terms of water related risks. While hydrological models are key tools to do so, their use in this part of the world is strongly limited by the scarcity of rainfall data. Satellite precipitation products can be used as rainfall input to models in order to make up for this shortage of appropriate surface data. However, these satellite products have their own weaknesses, both in terms of accuracy and resolution. While the accuracy of satellite rainfall estimates has already received a fair amount of attention, little published work deals with the resolution issue. The study presented here is motivated by this lack of attention to the resolution issue. It makes use of the data produced by a very dense rainfall network covering the Ouémé catchment in Benin $\left(14600 \mathrm{~km}^{2}\right)$, to study the impact of varying the space-time resolution of input rainfields on the output produced by DHSVM (Distributed Hydrology Soils and Vegetation Model), thus mimicking the resolution-induced errors associated with using satellite rainfall input for such physically-based models. The major result of this sensitivity analysis is that the model output is much more sensitive to the time resolution than to the space resolution, at least for this region and for the range of resolutions tested.
\end{abstract}

Key words rainfall; space-time variability; hydrological modelling; DHSVM; West Africa

\section{INTRODUCTION}

West Africa is well known for having experienced a severe drought since the end of the 1960s, but over the last two decades the region has also been increasingly affected by floods of unprecedented severity. Finely assessing the water related consequences of such climatological changes requires using hydrological models able to render the complexity of the river response to such changes. The range of scales that need to be considered in such studies is large - depending on the type of impact one has in mind - and so are the range of scales and resolutions that need to be documented by the hydro-meteorological data used either to force the model or to validate it. As soon as one gets interested in flood issues, forcing rainfields at high space-time resolution (typically kilometric in space and hourly - or less - in time) becomes an important need for accurately simulating the catchment response, or so is believed.

In many regions of the world, the available surface rainfall measurements do provide such high space-time resolution rainfields with a reasonable margin of uncertainty - this is notably the case for West Africa, where operational raingauge networks are characterised by low gauge density. Satellite precipitation products then become an attractive alternative to surface rainfall measurements for use as input to hydrological models. However, these satellite products have their own weaknesses. They are often characterised by a coarse spatial resolution and/or by a coarse time resolution, to smooth out their local errors in rainfall pattern and intensity estimates (see Gosset et al. 2013, for West Africa). The effect of the resolution of forcing rainfields on the performance of hydrological models has received little attention in the literature. In a previous study Vischel et al. (2007) quantified the errors generated when using rainfields for various degraded space and time resolutions in a Sahelian sub-region of West Africa. The Sahel being characterised by a semi-arid climate, the conclusions of Vischel et al. (2007) need to be revisited for the more humid regions of West Africa, where the most damaging floods occurred over the past 10 years or so. This is achieved here by using the data produced by a very dense rainfall network covering the Ouémé catchment in Benin $\left(14600 \mathrm{~km}^{2}\right)$. This dataset allows production of high space-time resolution rainfields that are then aggregated in time and space to study how using coarser resolutions affects the performance of the physically based hydrological model DHSVM (Distributed Hydrology Soil Vegetation Model; Wigmosta et al., 1994). This simulation procedure 
allows separation of two effects in the hydrological errors associated with satellite rainfall products: (i) the pure resolution effect; and (ii) the effect of these products incorrectly estimating rainfall patterns and intensities.

\section{REGION OF STUDY AND FORCING RAINFIELDS}

\section{The Ouémé catchment}

The Ouémé catchment (Fig. 1) is located in the north of Benin. It covers $14600 \mathrm{~km}^{2}$ spread over an undulating topography ranging in elevation from 250 to $500 \mathrm{~m}$. It is characterized by a Sudanian climate with a single rainy season from April to October and mean annual precipitation ranging from $1200 \mathrm{~mm}$ in the north to $1300 \mathrm{~mm}$ in the south. The temperature varies between $20^{\circ}$ and $35^{\circ} \mathrm{C}$ making evapotranspiration a major component of the water balance. The streamflows are of intermittent nature occurring mostly between the end of June and November.

\section{In situ hydrological data}

The Ouémé catchment is one of the three sites of the AMMA-CATCH observatory (African Monsoon Multidisciplinary Analysis - Coupling the Tropical Atmosphere and the Hydrological Cycle, Lebel et al., 2009), the two others being in Niger and Mali. At these sites specific instruments are dedicated to the measurement of meteorological variables (rainfall, radiations, and energy fluxes), soil and vegetation, soil moisture, water table and streamflow (Fig. 1).

For the present study, rainfall and streamflow data have been extracted from the AMMACATCH database (http://bd.amma-catch.org/amma-catch2/). During the study period, defined as between 2005 and 2008, two streamgauges were operating at the outlet of the main sub-basins of the Ouémé catchment: the Beterou station (drainage area $10050 \mathrm{~km}^{2}$ ) and the C238 station (drainage area $3100 \mathrm{~km}^{2}$ ) both providing continuous estimates of river discharge.

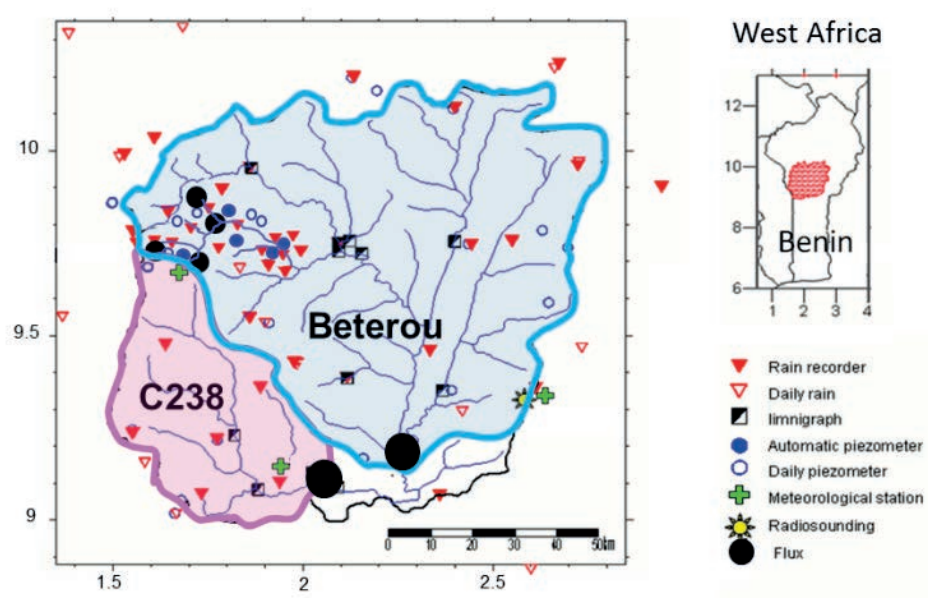

Fig. 1 Hydrometeorological network over the Ouémé catchment.

\section{Rainfall data and rainfields}

Rainfall data are collected by recording raingauges at high space sampling (one gauge every $20 \mathrm{~km}$ or so, and locally one gauge every km; a total of 54 gauges) and high time resolution (5 minutes). These raingauge data are used to generate rainfields by interpolating the point measurements, using the Lagrangian kriging approach proposed by Vischel et al. (2011). This method takes into account the propagation of the rainfall systems to interpolate rainfall, and was shown to improve the representation of the spatial intermittency and spatial variability of rainfall intensities compared to classical ordinary kriging. Reference rainfields are produced at a half-hourly time step over a $0.05^{\circ}$ resolution grid. 


\section{HYDROLOGICAL MODELLING}

\section{General description of DHSVM}

The Distributed Hydrology Soil Vegetation Model (DHSVM) is an open source physically-based distributed hydrological model designed to represent the effects of topography and vegetation on water fluxes through a catchment. The DHSVM structure is based on a digital elevation model (DEM) that quantifies topography and flow directions. Parameters are spatially distributed through soil and vegetation classes assigned to DEM cells. The most recent model equations and processes are detailed in Singh et al. (2002) and updated versions of the model are regularly provided and documented on the dedicated website maintained by the University of Washington.

\section{Model implementation}

The application of DHSVM to the Ouémé catchment has been motivated by the ALMIP2 project (AMMA Land surface Model Intercomparison Project - Phase 2; Boone et al. 2009) which aims to intercompare results from an ensemble of hydrologic and land surface models applied to the catchments of the AMMA-CATCH observatory. Topographical data are extracted from the SRTM 90-m DEM. The atmospheric data (air temperature, specific humidity at $2 \mathrm{~m}$, surface pressure and wind speed) are derived from the European Centre for Medium-Range Weather Forecasts (ECMWF) forecast data. Soil and vegetation maps come from the ECOCLIMAP-II database (Kaptue Tchuente et al. 2010). The reference rainfields (resolution of $0.05^{\circ}$ generated by interpolating the raingauge data are used as input to the model.

\section{Model initialization, calibration and evaluation}

The initialization of DHSVM is ensured by a spin-up realized over the first year of simulation. The poor performances of the first simulations obtained with the model parameters estimated a priori led us to calibrate the model. We only calibrated the most sensitive parameters according to the DHSVM literature and our own expertise gained through manual sensitivity analyses. The calibration process was performed manually and was based on streamflows of year 2005 measured at the $\mathrm{C} 238$ station (Fig. 1). The other years as well as the streamflow observations at the Beterou station, were used to evaluate the performance of the model, with no recalibration. The Nash and Sutcliffe efficiency (NSE) was used to evaluate the simulation performances (Fig. 2).
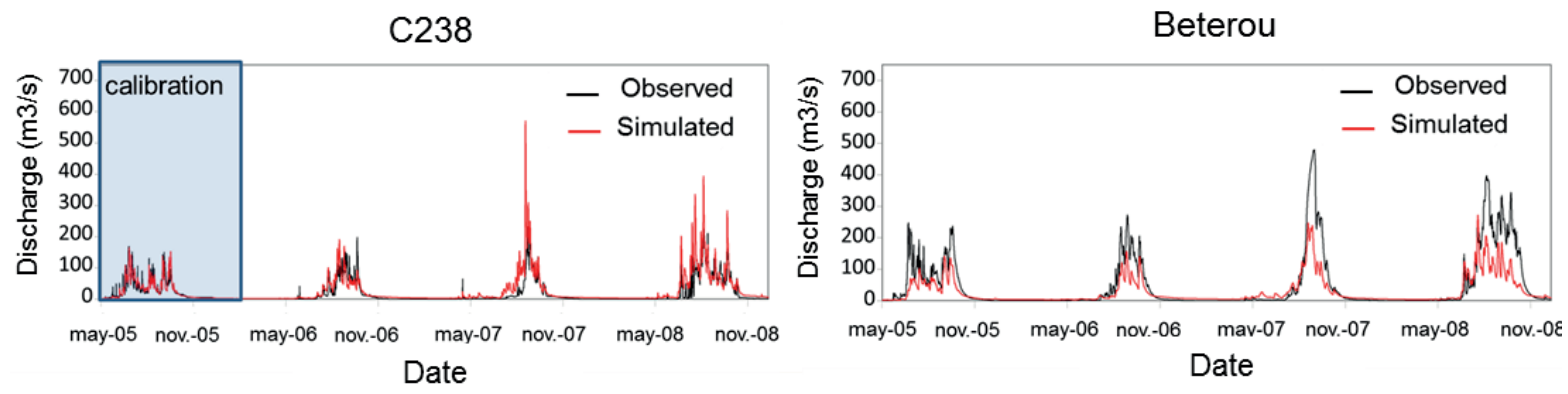

Fig. 2 Calibration and evaluation of the DHSVM simulations over the Ouémé catchment.

A good agreement is obtained in calibration between observation and simulation (NSE of 0.82 ). At the $\mathrm{C} 238$ station, the evaluation for the three following years at the same station shows a good representation of the interannual variability of streamflows, but an overestimation of the peak flows is noted, especially in 2007. However, the overall simulations are acceptable with the efficiency ranging from 0.71 for 2006 , to 0.54 for 2008. At the Beterou stations, the streamflow values are underestimated despite a good representation of the intra-seasonal variability, leading to lower efficiency values (of 0.57 in 2005 and 2008).

Obviously one can argue that the simulations could be perfected. However, our objective is not to get the best calibration but more to fairly represent the main hydrological processes to assess 
the sensitivity of a typical Sudanian catchment to rainfall variability. We thus consider that the model performances are sufficient and that the simulations presented in Fig. 2 can be used as a reference to evaluate the model sensitivity to rainfall variability.

\section{IMPACT OF RAINFALL AGGREGATION ON HYDROLOGICAL SIMULATIONS}

\section{Rainfall aggregation}

The rainfall sensitivity analysis is realized by separating the effect of spatial and temporal resolution on simulations. The reference rainfields (resolutions of 30 minutes and $0.05^{\circ}$ ) are spatially aggregated to resolutions of $0.1^{\circ}, 0.25^{\circ}$ and $0.5^{\circ}$ in space and to resolutions $1 \mathrm{~h}, 2 \mathrm{~h}, 6 \mathrm{~h}$ $12 \mathrm{~h}$ and $24 \mathrm{~h}$ in time. The aggregated rainfields are then used to force DHSVM without recalibration. It is noteworthy that the model time step and grid are kept at their initial resolution (30 minutes, $0.05^{\circ}$ ). This allows isolating the impact of rainfall resolution from any other effects (e.g. computational effect, change of topographic features, effects of other forcing variables). To do so, the aggregated rainfields are resampled at the initial model resolution. The effect of resolution is analysed by comparing the simulations obtained from coarse resolution rainfields with the reference simulations obtained with the finest resolution rainfields (Fig. 2).

\section{Impact of rainfall spatial resolution on hydrological simulations}

The effect captured by DHSVM from the spatial aggregation of the reference rainfall is presented in Fig. 3. Here, we show the influences over the annual volume of rainfields to resolutions $0.05^{\circ}$ $0.1^{\circ}, 0.25^{\circ}$ and $0.50^{\circ}$ over the domain of Benin catchment. Quite surprisingly the impact on streamflow simulations shown in Fig. 3 is very low. For both sub-basins, the simulated annual runoff is very similar for all resolutions, with differences always lower than $3 \%$. The insignificant changes in NSE with spatial resolution show that the overall pattern of the simulated hydrographs remains the same.
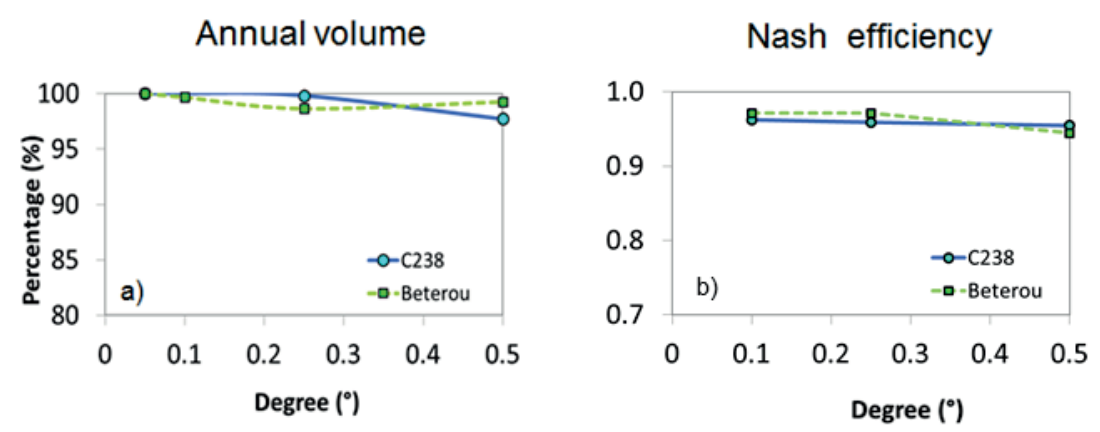

Fig. 3 Impact of rainfall spatial resolution on the simulated annual runoff of the Ouémé catchment. Changes (in \%) of the annual runoff volume (left) and Nash efficiency values of the simulated hydrographs (right). Simulations at resolution $0.05^{\circ}$ are taken as reference.
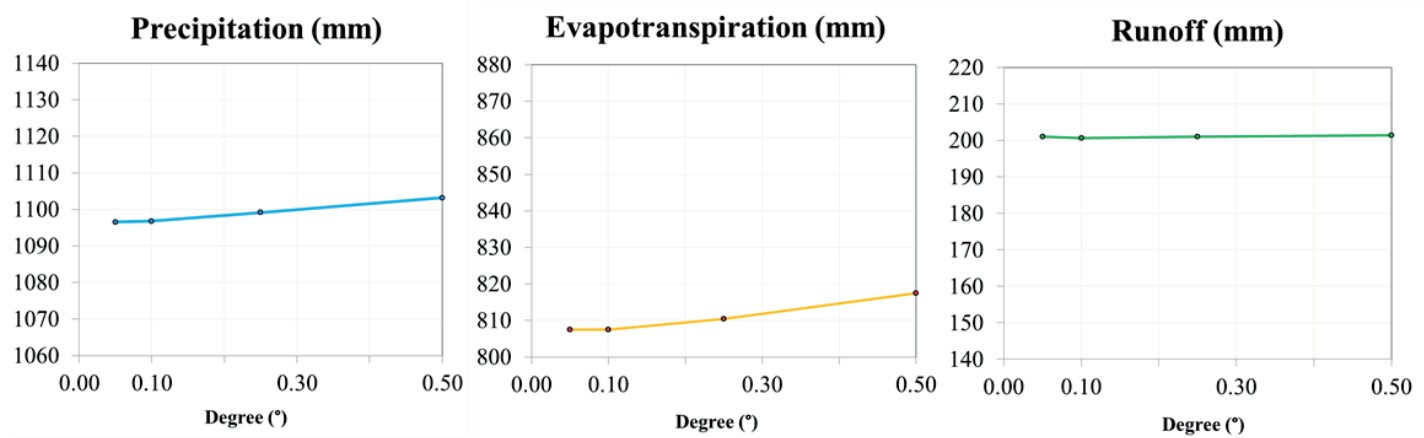

Fig. 4 Influence of rainfall spatial resolution on the components of the annual water balance of the Ouémé catchment. 
Figure 4 shows the impact of spatial resolution on the evolution of the mean annual rainfall, evapotranspiration and runoff. Although the aggregation process theoretically maintains the mean spatial rainfall over the square domain, a little increase (less than $1 \%$ ) of the computed annual precipitation is produced when increasing the spatial resolution. This is likely due to border effects generated by the aggregation process. Small changes of the annual evapotranspiration and of the annual runoff are observed as a direct consequence of this small change of the mean annual rainfall; however, given the level of accuracy of such hydrological simulations, one can consider all these small changes as non-significant.

\section{Impact of temporal resolution on hydrological simulations}

The impact of the temporal resolution on the hydrological simulations is shown in Fig. 5. The annual runoff over the two sub-basins steadily decreases with the time resolution. At the $24 \mathrm{~h}$ resolution it is almost $20 \%$ lower than at the 30 -min resolution. The decreasing values of NSE suggest that the time aggregation also modifies the shape of the simulated hydrographs. An analysis of the simulated hydrographs (not shown here) revealed that peak flows are significantly underestimated for coarse time resolution.
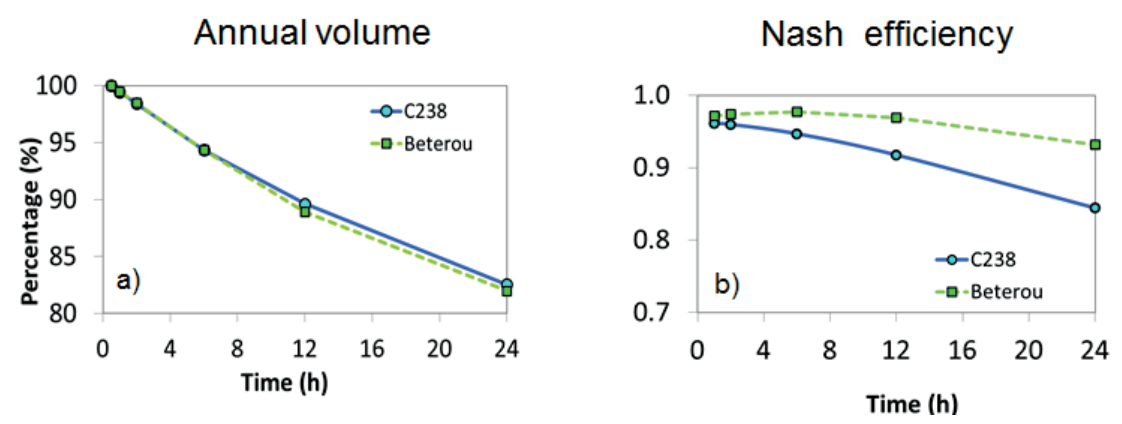

Fig. 5 Impact of rainfall temporal resolution on the simulated annual runoff of the Ouémé catchment Changes (in \%) of the annual runoff volume (left) and Nash efficiency values of the simulated hydrographs (right). Simulations at resolution 30 minute are taken as the reference.
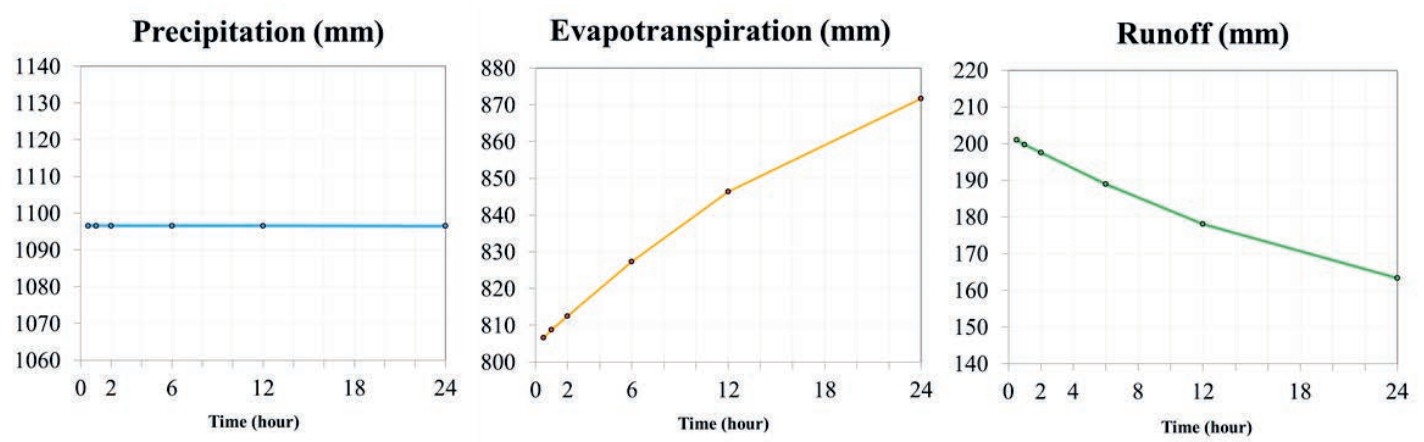

Fig. 6 Influence of the rainfall time resolution on the components of the annual water balance of the Ouémé catchment.

Figure 6 shows the effect of temporal aggregation on the three components of the water balance. The time resolution has no effect on the precipitation as amounts are conserved with aggregation (no temporal border effect). However, the time aggregation modifies the partition of the annual rainfall between evapotranspiration and runoff. Obviously, degrading the time resolution profoundly attenuates the rain intensities. Lower rainfall intensities are associated with the longer time steps, generating less runoff, which leaves more water to be stored in the soil, this water being later used to supply the evaporation demand. In contrast to what was observed when degrading the spatial resolution, the changes in evapotranspiration and runoff appear to be significant, reaching about $10 \%$ for the mean annual evapotranspiration and $15 \%$ for the annual 
runoff. All in all, this means that the annual evapotranspiration represents $73 \%$ of the annual rainfall at the finest resolution and $80 \%$ at the coarsest resolution.

\section{CONCLUSION AND DISCUSSION}

In regions like West Africa where in situ rainfall data are scarce, satellite rainfall are attractive alternatives when it comes to obtaining realistic inputs to hydrological models. However, beyond their difficulty to provide accurate rainfall estimate, satellite rainfall products often display spacetime resolutions that are much coarser than the resolutions required to force physically-based hydrological models. To evaluate the potential of satellite products for hydrological modelling studies in West Africa, the objective of the present work was to evaluate the impact of rainfall space-time resolution on a $14300 \mathrm{~km}^{2}$ catchment in Benin using the DHSVM model. After calibration, the hydrological model was shown to reasonably simulate the catchment hydrographs over a period of four years from 2005 to 2008. Using forcing rainfields computed for different spatial and time resolutions, it has been shown that: (i) spatial resolution has almost no effect on the simulated hydrographs and overall annual runoff and evapotranspiration; (ii) temporal aggregation has a significant effect on the simulated hydrograph shape and on the respective contributions of evapotranspiration and runoff to the catchment annual water balance.

These results contrast with those obtained by (Vischel and Lebel 2007) in Sahelian West Africa where the spatial and temporal resolutions were shown to both influence the calculation of the runoff and the evapotranspiration. The nature of rainfall might be an explanation for such differences as convective rainy systems in the Sahel are much more variable and intermittent than the rainy systems in the Sudanian region. But the most probable reason lies in the way runoff is produced over the catchment. Some authors (Obled et al. 1994) argue that catchments for which infiltration-excess (Hortonian) runoff mechanisms are preponderant, as in the Sahel, are more sensitive to the spatial variability of rainfall than catchments for which runoff is produced by saturation-excess runoff mechanisms as in the Sudanian region. The reason why time resolution strongly affects the simulations requires further investigation but it is clear from our results that accounting properly for the exact time sequence of rainfall intensities is required to properly model the peak flows of the hydrographs.

The next step of this study will be to evaluate the potential of satellite rainfall products to provide appropriate forcing variables for modelling the hydrology of the Ouémé catchment. According to our findings we can reliably state that the spatial resolution of the satellite rainfall products should not be a significant source of uncertainties in these hydrological simulations, while the time resolution will be more of an issue.

\section{REFERENCES}

Boone, A., et al. (2009) AMMA Land Surface Model Intercomparison Project Phase 2 (ALMIP-2). GEWEX News, 19(4).

Gosset, M., et al. (2013) Evaluation of several rainfall products used for hydrological applications over West Africa using two high-resolution gauge networks. Quarterly Journal of the Royal Meteorological Society, 139(673), 923-940.

Kaptue Tchuente, A. T. et al. (2010) ECOCLIMAP-II: An ecosystem classification and land surface parameters database of Western Africa at $1 \mathrm{~km}$ resolution for the African Monsoon Multidisciplinary Analysis (AMMA) project. Remote Sensing of Environment, 114(5), 961-976.

Lebel, T., et al. (2009) AMMA-CATCH studies in the Sahelian region of West-Africa: An overview. Journal of Hydrology, $375,3-13$.

Obled, C., Wendling, J. and Beven, K. (1994) The sensitivity of hydrological models to spatial rainfall patterns: an evaluation using observed data. Journal of Hydrology, 159, 305-333.

Vischel, T. and Lebel, T. (2007) Assessing the water balance in the Sahel: Impact of small scale rainfall variability on runoff. Part 2: Idealized modeling of runoff sensitivity. Journal of Hydrology, 333(2-4), 340-355.

Vischel, T., et al. (2011) Generation of high resolution rainfields in West Africa: evaluation of dynamical interpolation methods. Journal of Hydrometeorology, 110426113802000.

Wigmosta, M.S., Vail, L.W. and Lettenmaier, D.P. (1994) A distributed hydrology-vegetation model for complex terrain. Water Resources Research, 30(6), 1665-1679. 